Jurnal Indonesia Sosial Teknologi: p-ISSN: 2723 - 6609

e-ISSN : 2745-5254

Vol. 2, No. 4 April 2021

\title{
KAJIAN TEKNIS PELEDAKAN TERHADAP HASIL FRAGMENTASI PADA PELEDAKAN BATU GAMPING DI PT SEMEN PADANG
}

\author{
Ghanda, Riandi Jectio Firsta, Nanda Eris Hakim dan Aldo Pujalinar \\ Teknik Pertambangan Universitas Jambi \\ Email: ghandatambang15@gmail.com,riandijectiofirsta@gmail.com, \\ nandaerishakim@gmail.com, aldopuja88@gmail.com.
}

\section{Abstract}

PT Semen Padang is one of the companies engaged in the cement industry with the main ingredient of limestone and its products known as Padang cement. Limestone mining at PT Semen Padang is carried out using blasting methods. Besides being more cost and time efficient, it is expected to get good fragmentation results by not producing chunks making it easier to do loading activities. The result of good blasting fragmentation is influenced by several factors, one of which is the blasting geometry. This study aims to obtain an average fragmentation of P80, get the volume of explosive holes and get an average fragmentation that passes on a sieve $<100 \mathrm{~cm}$ using the quzram method. The blasting geometry, blasting pattern and drilling pattern used are in accordance with what was applied by PT Semen Padang and with 15 blasting attempts. The data collection method uses the photography method. While data processing is done using split desktop 2.0 software. The results obtained from this study that the average fragmentation of P80 for 15 times blasting is $44.66 \mathrm{~cm}$, the results of explosive perforated rock volume for Front 2 with Space $x$ Burden $(5 \mathrm{~m} \times 5 \mathrm{~m}$ ) obtained 250 BCM and Front 15 with Space $x$ Burden (4 mx $4 \mathrm{~m}$ ) obtained 160 BCM and the average size of the blasting fragmentation distribution that escaped at the sieve $<100 \mathrm{~cm}$ was $85.58 \%$ and the average that was left at the sieve> $100 \mathrm{~cm}$ was $14.42 \%$. Good fragmentation is one indicator that there is no problem in the explosion.

Kata kunci: limestone; blasting; fragmentation results

\begin{abstract}
Abstrak
PT Semen Padang merupakan salah satu perusahaan yang bergerak dalam industri semen dengan bahan utama batu gamping dan produknya yang di kenal dengan semen padang. Penambangan batu gamping di PT Semen Padang dilakukan menggunakan metode peledakan. Selain lebih efisien biaya dan waktu, diharapkan mendapatkan hasil fragmentasi yang baik dengan tidak menghasilkan bongkahan sehingga lebih mudah untuk dilakukan kegiatan loading. Hasil fragmentasi peledakan yang baik dipengaruhi oleh beberapa faktor salah satunya adalah geometri peledakan. Penelitian ini bertujuan untuk mendapatkan Fragmentasi ratarata P80, mendapatkan volume batuan perlubang ledak dan mendapatkan fragmentasi rata-rata yang lolos pada ayakan $<100 \mathrm{~cm}$ menggunakan metode kuzram. Geometri peledakan, pola peledakan dan pola pengeboran yang digunakan sesuai dengan metode yang diterapkan oleh PT Semen Padang dan dengan
\end{abstract}


percobaan 15 kali peledakan. Metode pengambilan data menggunakan metode fotografi. Sedangkan pengolahan data dilakukan menggunakan software split desktop 2.0. Hasil yang diperoleh dari penelitian ini bahwa rata-rata fragmentasi P80 untuk15 kali peledakan adalah $44,66 \mathrm{~cm}$, hasil volume batuan perlubang ledak untuk Front 2 dengan Spasi x Burden(5m x 5m) diperoleh 250 BCM dan Front 15 dengan Spasi x Burden (4 m x $4 \mathrm{~m}$ ) diperoleh $160 \mathrm{BCM}$ dan rata-rata distribusi fragmentasi peledakan ukuran yang lolos pada ayakan $<100 \mathrm{~cm}$ adalah $85,58 \%$ dan rata-rata yang tertingggal pada ayakan $>100 \mathrm{~cm}$ adalah 14,42\%. Fragmentasi baik merupakan salah satu indikator bahwa tidak ada masalah dalam peledakan tersebut.

Kata kunci: batu gamping; peledakan; hasil fragmentasi peledakan.

\section{Pendahuluan}

Batu gamping sendiri termasuk kedalam golongan batuan sediment ataupun batuan endapan. Batu gamping banyak mengandung kalsium dalam bentuk $\mathrm{CaCO}_{3}$ (Kalsium Karbonat) yang dapat dimanfaatkan lebih jauh untuk sumber daya manusia (Margareta, Fuad, Ilmiawati, \& Wonorahardjo, 2015). Bahan baku dalam pembuatan Semen Padang adalah batu gamping yang merupakan bahan utama dalam pembuatan semen ini. Banyaknya batu gamping yang di gunakan dalam pembuatan semen diantaranya $\pm 81 \%$ batu gamping dengan kadar air $\pm 5 \%$, tanah liat $\pm 9 \%$ dengan kadar air $\pm 20 \%$, pasir silika $\pm 9 \%$ dengan kadar $\mathrm{SiO}_{2} \pm 90 \%$ dan pasir besi $\pm 1 \%$ dengan $\mathrm{Fe}_{2} \mathrm{O}_{3} \pm 75 \%$ (Tampubolon, n.d.). Untuk mendapatkan batu gamping di lakukan dengan cara penambangan yaitu melalui proses peledakan. Tujuan pekerjaan peledakan yaitu memecah atau membongkar batuan kompak atau massive dari batuan induknya menjadi material yang cocok untuk dikerjakan dalam proses pembuatan semen (Hasyim, 2014).

Menurut (Herdy, 2015), Suatu operasi peledakan dinyatakan berhasil dengan baik pada kegiatan penambangan apabila target produksi terpenuhi, penggunaan bahan peledak efisien yang dinyatakan dalam jumlah batuan yang berhasil dibongkar per kilogram bahan peledak (yang disebut Powder Factor), diperoleh fragmentasi ukuran merata dengan sedikit bongkah (kurang dari 15\% dari jumlah batuan yang terbongkar perpeledakan). Fragmentasi yang diharapkan oleh perusahaan adalah fragmentasi yang ukurannya seragam. Perusahaan mengharapkan, $80 \%$ dari produk peledakan memiliki ukuran $<110 \mathrm{~cm}$. Fragmentasi yang memiliki ukuran $>100 \mathrm{~cm}$ (boulder), akan mempersulit perusahaan dalam proses crusher (Febrianto, Yulhendra, \& Abdullah, 2014). Penulis akan mengkaji kegiatan peledakan yang mempengaruhi tingkat fragmentasi peledakan batu gamping di PT Semen Padang.

\section{Metode Penelitian}

Penelitian ini menggunakan metode photograpic untuk mendapatkan distribusi fragmentasi. Metode photograpic adalah metode analisis image/gambar dengan menggunakan perangkat lunak (software). Software split desktop 2.0 digunakan untuk mendapatkan distribusi ukuran fragmentasi dimana hasilnya berupa: grafik persantase lolos material dan ukuran fragmentasi. Pengambilan data dilakukan di dua lokasi peledakan PT Semen Padang. Geometri peledakan yang di gunakan untuk front 2 dan front 15 terdapat perbedaan geometri yaitu penggunaan spasi dan burden, untuk front 2 menggunakan spasi x burden $(5 \mathrm{~m}$ x $5 \mathrm{~m}$ ) dan di front 15 menggunakan spasi x burden (4 $\mathrm{m} \times 4 \mathrm{~m}$ ), perbedaan penggunaan geometri di dasarkan oleh perbedaan keketuan 
batuan. Untuk pola pengeboran dan pola peledakan yang digunakan sama. Pengambilan foto fragmentasi dilakukan setelah kegiatan peledakan.

\section{Hasil dan Pembahasan \\ Geometri Peledakan}

Menurut (Herman, 2015) Geometri peledakan berpengaruh terhadap volume bongkaran batuan yang akan diledakkan. Adapun data-data yang dibutuhkan/diperoleh adalah kedalaman lubang ledak, pola peledakan, isian bahan peledak tiap lubang dan jumlah bahan peledak dalam satu kali kegiatan peledakan. Umumnya setiap peledakan menghendaki ukuran fragmentasi sesuai dengan target yang diterapkan. Fragmentasi terlalu besar (boulder) memerlukan pengolahan lanjutan agar pada proses peremukan batuan. Berikut adalah data geometri peledakan yang digunakan (lihat tabel 1):

Tabel 1 Geometri Peledakan PT Semen Padang

\begin{tabular}{cccccccccc}
\hline No & Lokasi & $\begin{array}{c}\text { Jumlah } \\
\text { lubang }\end{array}$ & $\begin{array}{c}\text { De } \\
(\mathbf{i n c h})\end{array}$ & $\begin{array}{c}\text { Burden } \\
(\mathbf{m})\end{array}$ & $\begin{array}{c}\text { Spacing } \\
(\mathbf{m})\end{array}$ & $\begin{array}{c}\text { Depth } \\
(\mathbf{m})\end{array}$ & $\begin{array}{c}\text { Stem } \\
\text { ming } \\
(\mathbf{m})\end{array}$ & $\begin{array}{c}\text { PC } \\
(\mathbf{m})\end{array}$ & $\begin{array}{c}\text { Height } \\
(\mathbf{m})\end{array}$ \\
\hline 1 & Front 2 & 30 & 5.5 & 5 & 5 & 10 & 5 & 5 & 10 \\
\hline 2 & Front 2 & 35 & 5.5 & 5 & 5 & 10 & 5 & 5 & 10 \\
\hline 3 & Front 2 & 30 & 5.5 & 5 & 5 & 10 & 5 & 5 & 10 \\
\hline 4 & Front 2 & 30 & 5.5 & 5 & 5 & 10 & 5 & 5 & 10 \\
\hline 5 & Front 2 & 35 & 5.5 & 5 & 5 & 10 & 5 & 5 & 10 \\
\hline 6 & Front 2 & 40 & 5.5 & 5 & 5 & 10 & 5 & 5 & 10 \\
\hline 7 & Front 2 & 44 & 5.5 & 5 & 5 & 10 & 5 & 5 & 10 \\
\hline 8 & Front 2 & 44 & 5.5 & 5 & 5 & 10 & 5 & 5 & 10 \\
\hline 9 & Front 15 & 61 & 5.5 & 4 & 4 & 10 & 5 & 5 & 10 \\
\hline 10 & Front 15 & 90 & 5.5 & 4 & 4 & 10 & 5 & 5 & 10 \\
\hline 11 & Front 15 & 70 & 5.5 & 4 & 4 & 10 & 5 & 5 & 10 \\
\hline 12 & Front 15 & 75 & 5.5 & 4 & 4 & 10 & 5 & 5 & 10 \\
\hline 13 & Front 15 & 50 & 5.5 & 4 & 4 & 10 & 5 & 5 & 10 \\
\hline 14 & Front 15 & 50 & 5.5 & 4 & 4 & 10 & 5 & 5 & 10 \\
\hline 15 & Front 15 & 60 & 5.5 & 4 & 4 & 10 & 5 & 5 & 10 \\
\hline Rata-rata & 49.6 & 5.5 & 4.46 & 4.46 & 10 & 5 & 5 & 10 \\
\hline
\end{tabular}

\section{Pola Pengeboran}

Pola pengeboran yang digunakan oleh PT Semen Padang adalah pola staggered dengan arah lubang tembak tegak lurus/vertikal dengan pola pengeboran staggered, diharapkan energi yang dihasilkan dari bahan peledak lebih efektif terdistribusi. Sehingga memungkinkan mendapatkan frgamentasi batuan yang seragam dan dapat meminimalisir terbentuknya boulder akibat pola pengeboran dan arah lemparan batuanya.

\section{Pola Peledakan}

Pola peledakan yang digunakan oleh perusahaan PT Semen Padang adalah pola peledakan row by row. Keadaan free face berada didepan dan diatas. Sedangkan, sistem rangkaian yang digunakan untuk merangkai pola pedakan di PT Semen Padang adalah sistem non elektrik (nonel). 


\section{Fragmentasi}

Menurut (Munawir, 2016) salah satu indikator untuk menentukan keberhasilan suatu kegiatan pemboran dan peledakan adalah tingkat fragmentasi batuan yang dihasilkan dari kegiatan pemboran dan peledakan tersebut. Diharapkan ukuran fragmentasi batuan yang dihasilkan sesuai dengan kebutuhan pada kegiatan penambangan selanjutnya. Bongkahan yang terbentuk dari hasil ledakan disebut over size (ukuran berlebihan), dan untuk mencegah terbentuknya bongkahan atau mendapatkan ukuran yang seragam sesuai dengan ukuran kebutuhan crusher, maka dibutuhkan keselarasan geometri peledakan dengan fragmentasi batuan hasil ledakan. Fragmentasi batuan yang memerlukan pemecahan ulang dinyatakan sebagai bongkah, Ada beberapa cara untuk mengetahui ukuran fragmentasi dan persentase kelolosan antara lain yaitu secara teoritis menggunakan metode Kuzram dan image analysis dengan menggunakan bantuan software split desktop 2.0. Berikut data penelitian yang dihitung dan dianalisis dengan kedua metode tersebut:

\section{Teoritis Metode Kuzram}

Ukuran fragmentasi dan persentase lolos bisa dihitung secara teoritis menggunakan metode Kuzram (Listine, Nurhakim, Dwiatmoko, \& Excelsior, 2015). Namun sebelum perhitungan dilakukan, ditentukan terlebih dahulu nilai faktor batuan. Nilai faktor batuan diperoleh dari pembobotan berdasarkan tabel klasifikasi blastability indeks. Berikut ini adalah pembobotan klasifikasi blastability indeks guna memperoleh nilai faktor batuan (lihat tabel 2).

Tabel 2 Pembobotan Blastability Indeks

\begin{tabular}{llll}
\hline No & Parameter & $\begin{array}{l}\text { Pembobotan } \\
\text { Batu Gamping }\end{array}$ & Keterangan \\
\hline 1 & Rock Mass Description (RMD) & 20 & Blocky \\
\hline 2 & Joint Plane Spacing (JPS) & 20 & Intermediet \\
\hline 3 & Joint Plane Orientation (JPO) & 20 & Dip Out of Face \\
\hline 4 & $\begin{array}{l}\text { Specivic Gravity Influence } \\
\text { (SGI) }\end{array}$ & 7,5 & $(25 \times 2,3)-50$ \\
\hline 5 & Hardness $(\mathrm{H})$ & 7,5 & 7,5 \\
\hline Total Pembobotan & 75 & \\
\hline
\end{tabular}

Berdasarkan hasil pembobotan pada tabel diatas, maka dapat diperhitungkan nilai blastability indeks dan faktor batuan berdasarkan Persamaan 12 sebagai berikut:

BI

$$
\begin{array}{ll}
\mathrm{BI} & =0,5 \times(\mathrm{RMD}+\mathrm{JPS}+\mathrm{JPO}+\mathrm{SGI}+\mathrm{H}) \\
& =0,5 \times(20+20+20+7,5+7,5)=37,5 \\
\text { Faktor Batuan } & =0,12 \times \mathrm{BI} \\
& =0,12 \times 37,5=4,5
\end{array}
$$

\begin{tabular}{|c|c|c|c|c|c|c|c|c|}
\hline No & Tanggal & Lokasi & $\begin{array}{l}\text { Jun } \\
\text { Lul }\end{array}$ & $\begin{array}{l}\overline{(X)} \\
(\mathbf{c m})\end{array}$ & $\mathbf{N}$ & $\begin{array}{l}\mathrm{Xc} \\
(\mathrm{cm})\end{array}$ & $\begin{array}{l}\text { Tertahan } \\
(\mathrm{R})(\%) \\
\geq 100 \mathrm{~cm}\end{array}$ & $\begin{array}{l}\text { Lolos } \\
(\mathrm{Y})(\%) \\
\geq 100 \\
\mathrm{~cm}\end{array}$ \\
\hline 1 & 17/09/2019 & Front 2 & 30 & 35,76 & 0,85 & 55,05 & $18,99 \%$ & $81,01 \%$ \\
\hline 2 & 18/09/2019 & Front 2 & 35 & 35,76 & 0,85 & 55,05 & $18,99 \%$ & $81,01 \%$ \\
\hline
\end{tabular}

Hasil dari perhitungan Kuzram ukuran fragmentasi dari tiga kegiatan peledakan seperti ditabulasikan dalam Tabel 3.

Tabel 3 Ukuran Fragmentasi Secara Teoritis Kuzram 


\begin{tabular}{lllllllll}
\hline 3 & $19 / 09 / 2019$ & Front 2 & 30 & 35,76 & 0,85 & 55,05 & $18,99 \%$ & $81,01 \%$ \\
\hline 4 & $20 / 09 / 2019$ & Front 2 & 30 & 35,76 & 0,85 & 55,05 & $18,99 \%$ & $81,01 \%$ \\
\hline 5 & $21 / 09 / 2019$ & Front 2 & 35 & 35,76 & 0,85 & 55,05 & $18,99 \%$ & $81,01 \%$ \\
\hline 6 & $22 / 09 / 2019$ & Front 2 & 40 & 35,76 & 0,85 & 55,05 & $18,99 \%$ & $81,01 \%$ \\
\hline 7 & $23 / 09 / 2019$ & Front 2 & 44 & 35,76 & 0,85 & 55,05 & $18,99 \%$ & $81,01 \%$ \\
\hline 8 & $24 / 09 / 2019$ & Front 2 & 44 & 35,76 & 0,85 & 55,05 & $18,99 \%$ & $81,01 \%$ \\
\hline 9 & $27 / 09 / 2019$ & Front15 61 & 25,02 & 0,89 & 37,78 & $9,2 \%$ & $90,8 \%$ \\
\hline 10 & $30 / 09 / 2019$ & Front15 90 & 25,02 & 0,89 & 37,78 & $9,2 \%$ & $90,8 \%$ \\
\hline 11 & $01 / 10 / 2019$ & Front15 70 & 25,02 & 0,89 & 37,78 & $9,2 \%$ & $90,8 \%$ \\
\hline 12 & $02 / 10 / 2019$ & Front15 75 & 25,02 & 0,89 & 37,78 & $9,2 \%$ & $90,8 \%$ \\
\hline 13 & $03 / 10 / 2019$ & Front15 50 & 25,02 & 0,89 & 37,78 & $9,2 \%$ & $90,8 \%$ \\
\hline 14 & $04 / 10 / 2019$ & Front15 50 & 25,02 & 0,89 & 37,78 & $9,2 \%$ & $90,8 \%$ \\
\hline 15 & $05 / 10 / 2019$ & Front15 60 & 25,02 & 0,89 & 37,78 & $9,2 \%$ & $90,8 \%$ \\
\hline & Rata - rata & $\mathbf{4 9}$ & $\mathbf{3 0 , 7 5}$ & $\mathbf{0 , 8 7}$ & $\mathbf{3 6 , 7 0}$ & $\mathbf{1 4 , 4 2 \%}$ & $\mathbf{8 5 , 5 8 \%}$ \\
\hline
\end{tabular}

\section{Software Split Desktop 2.0}

Foto fragmentasi dari kegiatan peledakan yang diteliti diolah dengan menggunakan bantuan software split desktop 2.0. Hasil pengolahan menggunakan split desktop 2.0 tersebut maka didapatkan hasil distribusi fragmentasi serta ukuran dari fragmentasi. Berdasarkan ketentuan PT Semen Padang maka digunakanlah ukuran fragmentasi P80 dari tabel distribusi hasil pengolahan menggunakan split desktop 2.0. sehingga diperoleh hasil fragmentasi rata-rata P80 seperti Tabel 4.

Tabel 4 Fragmentasi Rata-rata P80

\begin{tabular}{ccccc}
\hline No & Tanggal & Lokasi & $\begin{array}{c}\text { Jumlah } \\
\text { Lubang }\end{array}$ & $\begin{array}{c}\boldsymbol{P ~ 8 0} \\
\text { cm }\end{array}$ \\
\hline 1 & $17 / 09 / 2019$ & Front 2 & 30 & 26,61 \\
\hline 2 & $18 / 09 / 2019$ & Front 2 & 35 & 52,34 \\
\hline 3 & $19 / 09 / 2019$ & Front 2 & 30 & 37,45 \\
\hline 4 & $20 / 09 / 2019$ & Front 2 & 30 & 54,74 \\
\hline 5 & $21 / 09 / 2019$ & Front 2 & 35 & 37,33 \\
\hline 6 & $22 / 09 / 2019$ & Front 2 & 40 & 36,45 \\
\hline 7 & $23 / 09 / 2019$ & Front 2 & 44 & 28,86 \\
\hline 8 & $24 / 09 / 2019$ & Front 2 & 44 & 41,53 \\
\hline 9 & $27 / 09 / 2019$ & Front15 & 61 & 47,42 \\
\hline 10 & $30 / 09 / 2019$ & Front 15 & 90 & 57,69 \\
\hline 11 & $01 / 10 / 2019$ & Front15 & 70 & 51,90 \\
\hline 12 & $02 / 10 / 2019$ & Front15 & 75 & 49,82 \\
\hline 13 & $03 / 10 / 2019$ & Front15 & 50 & 60,26 \\
\hline 14 & $04 / 10 / 2019$ & Front15 & 50 & 30,88 \\
\hline 15 & $05 / 10 / 2019$ & Front15 & 60 & 53,74 \\
\hline & Rata - rata & & & $\mathbf{4 4 , 6 6}$ \\
\hline
\end{tabular}

\section{Pembahasan}

Suatu peledakan nilai geometri dapat dikatakan sangat penting untuk mengontrol fragmentasi batuan yang dihasilkan dan perlu adanya perhitungan yang lebih spesifik agar dapat mengontrol fragmentasi sesuai dengan yang diinginkan (Permana \& Heriyadi, 2019). Keberhasilan suatu peledakan ditentukan oleh ukuran fragmentasi batuan sehingga ukuran fragmentasi sangat penting untuk diperhatikan. 
Energi ledakan yang di hasilkan di front 2 lebih kecil dibandingkan di front 15 karena terdapat perbedaan geometri peledakan yang digunakan, kerapatan burden dan spasi tentunya mempengaruhi energi ledakan yang di hasilkan.

Burden dan spasi yang besar tentunya membuat energi ledakan sulit memecahkan suatu batuan kerena penyebaran energi yang di jangkau cukup luas mengakibatkan hilangnya energi ledakan sebelum sampai di batuan, berbeda dengan penggunaan burden dan spasi yang rapat justru menghasilkan energi yang optimal dikarenakan energi tersebut mencapai batuan sebelum energinya hilang. Hal ini sesuai dengan pernyataan (Rinaldo, Heriyadi, \& Prabowo, 2018) bahwa semakin besar volume batuan yang terbongkar semakin sedikit powder factor dan hasil fragmentasi yang di hasilkan juga akan besar, sebaliknya semakin kecil volume batuan yang terbongkar semakin banyak powder factor menghasilkan fragmentasi yang kecil. Semakin besar geometri peledakan maka semakin besar pula fragmentasi batuan hasil peledakan yang dihasilkan sebaliknya, semakin kecil geometri peledakan maka semakin kecil pula fragmentasi peledakan yang dihasilkan.

Berdasarkan pernyataan tersebut peningkatan jumlah Powder factor ini juga dipengaruhi oleh geometri dari peledakan tersebut karena geometri yang digunakan di front 2 khususnya spasi dan burdennya lebih besar dibandingkan dengan front 15 , dengan nilai burden $5 \mathrm{~m}$ x $5 \mathrm{~m}$ dan untuk Front 15 dengan nilai burden dan spasi $4 \mathrm{~m} \mathrm{x}$ $4 \mathrm{~m}$.

\section{Kesimpulan}

PT Semen Padang menerapkan geometri peledakan dengan burden $5 \mathrm{~m}$, spasi 5 $\mathrm{m}$, stemming $5 \mathrm{~m}$, powder charge $(\mathrm{PC}) 5 \mathrm{~m}$, subdrilling $1 \mathrm{~m}$, kedalaman lubang ledak $10 \mathrm{~m}$, dan ketinggian jenjang $10 \mathrm{~m}$ untuk front 2 dan front 15 menggunakan burden 4 $\mathrm{m}$, spasi $4 \mathrm{~m}$, stemming $5 \mathrm{~m}$, powder charge (PC) $5 \mathrm{~m}$, subdrilling $1 \mathrm{~m}$, kedalaman lubang ledak $10 \mathrm{~m}$, dan ketinggian jenjang $10 \mathrm{~m}$. Serta, pola pengeboran staggered dengan arah lubang tembak tegak lurus/vertikal dan pola peledakan row by row dengan rangkain non elektrik. Semakin besar spasi dan burden maka semakin besar volume batuan yang terbongkar dan semakin kecil spasi dan burden maka semakin kecil volume batuan yang terbongkar akan tetapi spasi dan burden yang besar justru mampu mengurangi pemakaian bahan peledak dan sebaliknya. 
Kajian Teknis Peledakan Terhadap Hasil Fragmentasi pada Peledakan Batu Gamping di PT Semen Padang

\section{Bibliografi}

Febrianto, Febrianto, Yulhendra, Dedi, \& Abdullah, Rijal. (2014). Perencanaan ulang geometri peledakan untuk mendapatkan fragmentasi yang optimum di lokasi penambangan front iv quarry pt. Semen padang. Bina Tambang, 1(1), 11-20.

Hasyim, Ibnu. (2014). Kajian geometri peledakan terhadap fragmentasi batuan hasil peledakan di pit 4 tuc pt. Mega prima persada kecamatan loa kulu kutai kartanegara kalimantan timur. Jurnal Geologi Pertambangan (JGP), 2(16).

Herman, Herman. (2015). Analisis Pengaruh Kedalaman Lubang Ledak, Burden Dan Spacing Terhadap Perolehan Fragmentasi Batugamping. Jurnal Geomine, 3(1).

Listine, Ditta, Nurhakim, Nurhakim, Dwiatmoko, Marselinus Untung, \& Excelsior, T. P. (2015). Studi teknis penentuan geometri peledakan dan powder factor (pf) pada pembongkaran bijih besi di pt putera bara mitra, desa mentawakan mulya kec. Mantewe, kab. Tanah bumbu, kalimantan selatan. Jurnal Geosapta, 1(01).

Margareta, Mailinda Ayu Hana, Fuad, Abdulloh, Ilmiawati, Siti Alfiah, \& Wonorahardjo, Surjani. (2015). Sintesa Hydroxyapatite (Ca10 (PO4) 6 (OH) 2) Berbasis Batu Kapur. Jurnal Penelitian Fisika Dan Aplikasinya (JPFA), 5(1), 1520.

Munawir, Munawir. (2016). Analisis Geometri Peledakan Terhadap Ukuran Fragmentasi Overburden Pada Tambang Batubara PT. Pamapersada Nusantara Jobsite Adaro Kalimantan Selatan. Jurnal Geomine, 1(1).

Permana, Ahmad Ridho, \& Heriyadi, Bambang. (2019). Kajian Pengurangan Getaran Tanah (Ground vibration) Pada Peledakan Overburden Tambang Batubara Di PT. Artamulia TataPratama Site Tanjung Belit Provinsi Jambi. Bina Tambang, 4(1), 344-356.

Rinaldo, Riki, Heriyadi, Bambang, \& Prabowo, Heri. (2018). Analisis Pengaruh Parameter Geomekanika Batuan Terhadap Kegiatan Peledakan Pada Front Penambangan Blok A2 di CV. Triarga Nusatama, Kecamatan Lareh Sago Halaban, Kabupaten Lima Puluh Kota, Sumatera Barat. Bina Tambang, 3(3), 1163-1173.

Saputra, Herdy Adi. (2015). Analisis Pengaruh Powder Factor terhadap Hasil Fragmentasi Peledakan Padapt. Semen Bosowa Maros Provinsi Sulawesi Selatan. Jurnal Geomine, 3(1).

Tampubolon, Gindo. (n.d.). Kajian teknis peledakan terhadap hasil fragmentasi pada peledakan batu gamping di pt. Semen padang. Jurnal Teknik Kebumian. 